\title{
FURTHER EXTENSION OF FURUTA INEQUALITY
}

\author{
ChANGSEN YANG AND YAQING WANG
}

Abstract. If $A_{2 n} \geqslant A_{2 n-1} \geqslant \cdots \geqslant A_{2} \geqslant A_{1} \geqslant B \geqslant 0$, with $A_{1}>0, t_{1}, t_{2}, \cdots, t_{n-1}, t_{n} \in[0,1]$ and $p_{1}, p_{2}, \cdots, p_{2 n-1}, p_{2 n} \geqslant 1$ for a natural number $n$. Then the following inequality holds for $r \geqslant t_{n}$

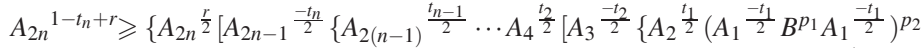

$$
\begin{aligned}
& \left.\left.\left.\left.\left.A_{2} \frac{t_{1}}{2}\right\}^{p_{3}} A_{3} \frac{-t_{2}}{2}\right]^{p_{4}} A_{4} \frac{t_{2}}{2} \cdots A_{2(n-1)^{\frac{t_{n-1}}{2}}}\right\}^{p_{2 n-1}} A_{2 n-1} \frac{-t_{n}}{2}\right]^{p_{2 n}} A_{2 n^{\frac{r}{2}}}\right\}^{\frac{1-t_{n}+r}{\partial[2 n]-t_{n}+r}},
\end{aligned}
$$

where $\partial[2 n]=\left\{\cdots\left[\left\{\left[\left(p_{1}-t_{1}\right) p_{2}+t_{1}\right] p_{3}-t_{2}\right\} p_{4}+t_{2}\right] p_{5}-\cdots-t_{n}\right\} p_{2 n}+t_{n}$.

Mathematics subject classification (2010): 47A63. equality.

Keywords and phrases: Furuta inequality, generalized Furuta inequality, order preserving operator in-

\section{REFERENCES}

[1] T. Ando And F. HiAI, Log majorization and complementary Golden-Thompson type inequalities, Linear Alg. and Its Appl., 197, 198 (1994), 113-131.

[2] M. FuJII, Furuta's inequality and its mean theoretic approach, J. Operator Theory, 23 (1990), 67-72.

[3] M. FujiI AND E. KAMEI, Mean theoretic approach to the grand Furuta inequality, Proc. Amer. Math. Soc., 124 (1996), 2751-2756.

[4] M. Fuji, E. KAMEI AND R. NAKAMoto, Grand Furuta inequality and its variant, J. Math. Inequal., 1 (2007), 437-441.

[5] M. Fujil, A. Matsumoto And R. NaKamoto, A short proof of the best possibility for the grand Furuta inequality, J. of Inequal. and Appl., 4 (1999), 339-344.

[6] T. FURUTA, Invitation to Linear Operators, Taylor \& and Francis, London, 2001.

[7] T. FURUTA, Further extension of an order perserving operator inequality, J. Math. Inequal, 2 (2008), 465-472.

[8] T. FurutA, An extension of the Furuta inequality and Ando-Hiai log majorization, Linear Alg. and Its Appl, 219 (1995), 139-155.

[9] T. FURUTA, Simplified proof of an order perserving operator inequality, Proc. Japan Acad., 74 (1998), 114.

[10] T. FuRUTA, A proof of an order preserving inequality, Proc. Japan Acad., 78, Ser. A (2002), 26.

[11] T. FURUTA, $A \geqslant B \geqslant 0$ assures $\left(B^{r} A^{p} B^{r}\right)^{\frac{1}{q}} \geqslant B^{\frac{p+2 r}{q}}$ for $r \geqslant 0, p \geqslant 0, q \geqslant 1$ with $(1+2 r) q \geqslant p+2 r$, Proc. Amer. Math. Soc, 101 (1987), 85-88.

[12] T. FuRUTA, Elementary proof of an order perserving inequality, Proc. Japan. Acad., 65 (1989), 126.

[13] T. Furuta, M. Hashimoto AND M. ITO, Equivalence relation between generalized Furuta inequality and related operator functions, Scienticae Mathematicae, 1 (1998), 257-259.

[14] T. Furuta, M.YANAGIDA AND T.YAMAZAKI, Operator functions implyimg Furuta inequalitty, Math. Inequal. Appl., 1 (1998), 123-130.

[15] E. HeInZ, Beiträge zur Störungsteorie der Spektralzerlegung, Math. Ann, 123 (1951), 415-438.

[16] F. Hansen, An operator inequality, Math. Ann., 246 (1980), 249-250.

[17] E. KameI, A sattelite to Furuta's inequality, Math. Japon, 33 (1988), 883-886.

[18] K. LöWnER, Über monotone Matrixfunktionen, Math. Z., 38 (1934), 177-216.

[19] G.K. Pedersen, Some operator monotone functions, Proc. Amer. Math. Soc, 36 (1972), 309-310.

[20] K. Tanahashi, Best possibility of Furuta inequality, Proc. Amer. Math. Soc., 124 (1996), 141-146. 
[21] K. Tanahashi, The best possibility for the grand Furuta inequality, Proc. Amer. Math. Soc., 128 (1999), 511-519.

[22] M. Uchiyama, Criteria for monotonicity of operator means, J. Math. Soc. Japan, 55 (2003), $197-$ 207.

[23] T. YAmaZAKI, Simplified proof of Tanahashi's result on the best possibility of generalized Furuta inequality, Math. Inequal. Appl., 2 (1999), 437-477. 